\title{
Erratum to: Tribological Performance of Halogen-Free Ionic Liquids as Lubricants of Hard Coatings and Ceramics
}

\author{
Yuriko Kondo • Takahiro Koyama • \\ Ryo Tsuboi - Miki Nakano - Koji Miyake • \\ Shinya Sasaki
}

Published online: 4 July 2013

(c) Springer Science+Business Media New York 2013

\section{Erratum to: Tribol Lett \\ DOI 10.1007/s11249-013-0159-1}

The original version of article unfortunately contained a mistake.

The presentation of Table 3 was incorrect. The correct Table 3 is given below.

The presentation of Fig. 2 was incorrect. The correct Fig. 2 is given below.

The presentation of Fig. 3 was incorrect. The correct Fig. 3 is given below.

Section 3.1 contained four missing sentences. The correct sentences are given below.

1. Second paragraph, L2 "On the other hand, the friction coefficient of $\mathrm{Si}_{3} \mathrm{~N}_{4}$ lubricated with [EMIM] [DCN] was higher than that of $\mathrm{SiC} . "$

2. Second paragraph, L5 "On the other hand, when [EMIM] [DCN] was used, a remarkable difference was observed between the friction behaviors of $\mathrm{Si}_{3} \mathrm{~N}_{4}$ and the others."

3. Second paragraph, L6 "Though $\mathrm{Si}_{3} \mathrm{~N}_{4}$ had the smoothest surface of all ceramics, its friction coefficient showed the highest value."

4. Second paragraph, L8 "However, the friction coefficient of $\mathrm{Si}_{3} \mathrm{~N}_{4}$, which had the smoothest surface $\left(R_{a}=0.020\right)$, was higher than those of the others."

Section 4 contained two missing sentences. The correct sentences are given below.

1. First paragraph, L2 "However, when [EMIM] [DCN] was used, the friction coefficient of $\mathrm{Si}_{3} \mathrm{~N}_{4}$ was higher than those of the other ceramics."

2. Second paragraph, L2 "[BMIM] [TCC] showed a lower friction coefficient for $\mathrm{CrN}$ and $\mathrm{TiN}$ than [EMIM] [DCN]; however, TiCN and TiAlN showed the opposite tendency."

The online version of the original article can be found under doi: 10.1007/s11249-013-0159-1.

Y. Kondo · T. Koyama - R. Tsuboi - S. Sasaki

Tokyo University of Science, 6-3-1 Niijyuku, Katsushika-ku,

Tokyo 125-8585, Japan

M. Nakano · K. Miyake · S. Sasaki ( $\square)$

AIST, 1-2-1 Namiki, Tsukuba, Ibaraki 305-8564, Japan

e-mail: s.sasaki@rs.tus.ac.jp 
Table 3 Physical properties of each material

\begin{tabular}{lllll}
\hline Material & Method & $\begin{array}{l}\text { Roughness } \\
(\mu \mathrm{m})\end{array}$ & $\begin{array}{l}\text { Hardness } \\
(\mathrm{GPa})\end{array}$ & Remark \\
\hline $\mathrm{CrN}$ & AIP & 0.028 & 26 & \\
$\mathrm{TiN}$ & AIP & 0.019 & 30 & \\
$\mathrm{TiCN}$ & AIP & 0.025 & 41 & \\
$\mathrm{TiAlN}$ & AIP & 0.008 & 16 & \\
$\mathrm{H}-$ free DLC & AIP & 0.012 & 73 & $\mathrm{H}=0$ at.\% \\
& & & & Interlayer: $\mathrm{Cr}$ \\
PVD-DLC & UBMS & 0.032 & 28 & $\mathrm{H}=20$ at.\% \\
& & & & Interlayer: $\mathrm{Cr}$ \\
$\mathrm{CVD}-\mathrm{DLC}$ & RF plasma CVD & 0.006 & 24 & $\mathrm{H}=30$ at.\% \\
& & & & Interlayer: $\mathrm{Si}$ \\
$\mathrm{Al}_{2} \mathrm{O}_{3}$ & Sintering & 0.253 & 18 & \\
$\mathrm{SiC}$ & Sintering & 0.109 & 22 & \\
$\mathrm{Si}_{3} \mathrm{~N}_{4}$ & Sintering & 0.020 & 14 & \\
\hline
\end{tabular}

Film thickness of all coatings was $1 \mu \mathrm{m}$

$A I P$ arc ion plating, UBMS unbalanced magnetron spattering

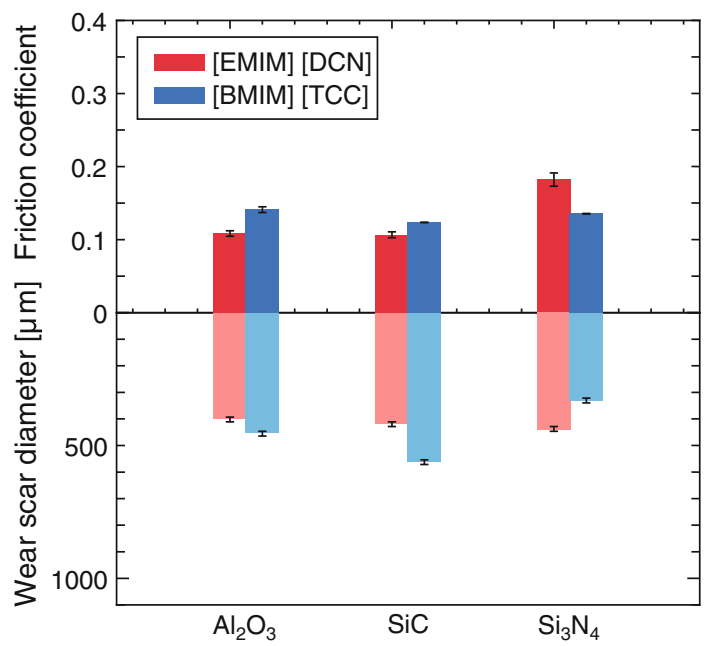

Fig. 2 Friction coefficient and wear scar diameter of each ceramic (a)

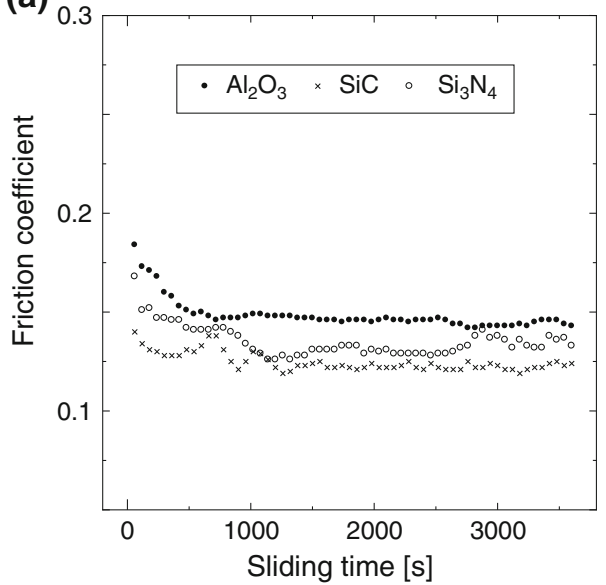

(b)

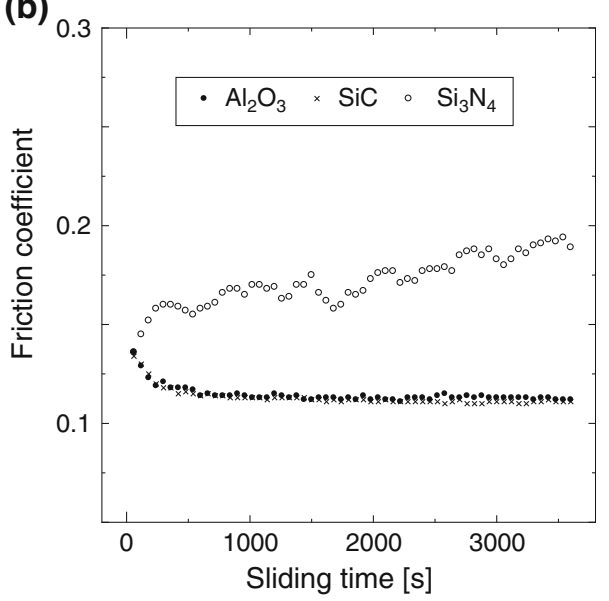

Fig. 3 Friction behavior of ceramics with a [BMIM] [TCC] and b [EMIM] [DCN] 